\title{
Protective effect of Bu-7, a flavonoid extracted from Clausena lansium, against rotenone injury in PC12 cells
}

\author{
Bo-yu LI, Yu-he YUAN, Jin-feng HU, Qing ZHAO, Dong-ming ZHANG, Nai-hong CHEN* \\ State Key Laboratory of Bioactive Substances and Functions of Natural Medicines, Institute of Materia Medica, Chinese Academy of \\ Medical Sciences and Peking Union Medical College, Beijing 100050, China
}

\begin{abstract}
Aim: To investigate the protective effect and underlying mechanisms of Bu-7, a flavonoid isolated from the leaves of Clausena lansium, against rotenone-induced injury in PC12 cells.

Methods: The cell viability was evaluated using MTT assay. The cell apoptosis rate was analyzed using flow cytometry. JC-1 staining was used to detect the mitochondrial membrane potential (MMP). Western blotting analysis was used to determine the phosphorylation of c-Jun N-terminal kinase (JNK), p38 mitogen-activated protein kinase (p38), tumor protein 53 (p53), Bcl-2-associated X protein (Bax), B-cell lymphoma 2 (Bcl-2), and caspase 3.

Results: Treatment of PC12 cells with rotenone (1-20 $\mu \mathrm{mol} / \mathrm{L})$ significantly reduced the cell viability in a concentration-dependent manner. Pretreatment with Bu-7 (0.1 and $10 \mu \mathrm{mol} / \mathrm{L})$ prevented PC12 cells from rotenone injury, whereas Bu-7 (1 $\mu \mathrm{mol} / \mathrm{L})$ had no significant effect. Pretreatment with Bu-7 (0.1 and $10 \mu \mathrm{mol} / \mathrm{L})$ decreased rotenone-induced apoptosis, attenuated rotenone-induced mitochondrial potential reduction and suppressed rotenone-induced protein phosphorylation and expression, whereas Bu-7 (1 $\mu \mathrm{mol} / \mathrm{L}$ ) did not cause similar effects. Bu-7 showed inverted bell-shaped dose-response relationship in all the effects.

Conclusion: Bu-7 protects PC12 cells against rotenone injury, which may be attributed to MAP kinase cascade (JNK and p38) signaling pathway. Thus, Bu-7 may be a potential bioactive compound for the treatment of Parkinson's disease.
\end{abstract}

Keywords: Bu-7; Clausena lansium; neuroprotection; Parkinson's disease; rotenone; apoptosis; PC12 cells

Acta Pharmacologica Sinica (2011) 32: 1321-1326; doi: 10.1038/aps.2011.119; published online 3 Oct 2011

\section{Introduction}

Parkinson's disease (PD) is a major age-related neurodegenerative disorder which is accompanied primarily by motor symptoms, such as resting tremor, rigidity and bradykinesia. It is pathologically characterized by the loss of dopaminergic neurons in the substantia nigra pars compacta (SNpc) and the accumulation of aggregated alpha-synuclein in brain stem, spinal cord, and cortex ${ }^{[1]}$. Several lines of evidence have converged to suggest that environmental neurotoxins, such as rotenone ${ }^{[2]}$, and mutant proteins, such as DJ-1, PINK1, and LRRK ${ }^{[3]}$, may be importantly involved in the etiopathogenesis of PD.

Long-term, systemic administration of rotenone, a natural substance which is widely used as a pesticide, produces the selective degeneration of dopaminergic neurons and PD-like locomotor symptoms in rats ${ }^{[2]}$. Among the various animal

\footnotetext{
* To whom correspondence should be addressed.

E-mail chennh@imm.ac.cn

Received 2011-05-11 Accepted 2011-07-20
}

models of PD, the rotenone model has its own advantages. Firstly, unlike the other models, it reproduces most of the movement disorder symptoms and the histopathological features of PD, including Lewy bodies ${ }^{[4,5]}$. Secondly, rotenone is a powerful inhibitor of complex I in the mitochondrial respiration, and recent epidemiological studies suggest the involvement of these toxic compounds in the higher incidence of sporadic Parkinsonism ${ }^{[6-8]}$. Observations have shown that a defect in mitochondrial complex I activity may induce the apoptosis of dopaminergic cells, which may contribute to the neurodegenerative process in $\mathrm{PD}^{[9]}$. Administration of rotenone has been used extensively to create PD models to screen for neuroprotective agents both in vivo ${ }^{[10,11]}$ and in vitro ${ }^{[12,13]}$.

Therapeutic efforts aimed at providing protection against apoptosis may be beneficial in PD. In this regard, natural products are attractive sources of chemical structures that could exhibit potent biological activities. Clausena lansium is a fruit tree native to the south of China, and a decoction of its dried leaves was used to treat acute and chronic viral hepatitis in local folk medicine ${ }^{[14]}$. More recently, there has been 
renewed interest in the neuroprotective potential of the leaf extracts of Clausena lansium; for example, research has been carried out on the effects of clausenamide in enhancing learning and memory ${ }^{[15,16]}$. In a previous attempt to detect more information about the biological activities of Clausena lansium, we separated the natural chemicals systematically from the leaves ${ }^{[17]}$. After preliminary screening, we found that one compound, termed Bu-7, was a biologically active substance. This is a known compound ${ }^{[18]}$, and the chemical structure of Bu-7 is shown in Figure 1.

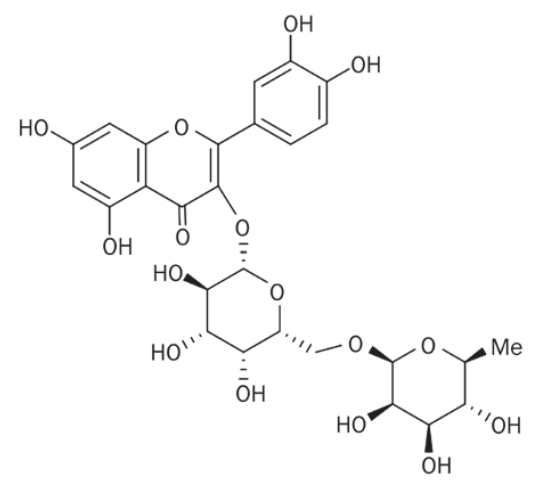

Figure 1. The chemical structure of Bu-7.

PC12 cells, a cell line established from a rat pheochromocytoma, have many properties in common with primary sympathetic neurons and chromaffin cell cultures, and these cells have been used primarily as neuron models ${ }^{[19]}$. In this article, we report the protective effect of $\mathrm{Bu}-7$ in $\mathrm{PC} 12$ cells against rotenone injury.

\section{Materials and methods Drugs and reagents}

Bu-7 was provided by the Department of Medicinal Chemistry, Institute of Materia Medica, Chinese Academy of Medical Sciences \& Peking Union Medical College (Beijing, China). Rotenone, 6-OHDA and 1-methyl-4-phenylpyridinium (MPP $\left.{ }^{+}\right)$ were purchased from Sigma-Aldrich (St Louis, MO, USA). 3-(4,5-Dimethylthiazol-2-yl)-2,5-diphenyl-tetrazolium bromide (MTT) and propidium iodide (PI) were purchased from Sigma Chemical Company (USA). JC-1 and Rhodamine 123 were purchased from Beyotime (China). Primary antibodies and secondary antibodies were purchased from Cell Signaling Technology (USA). All other chemicals were of analytical grade and commercially available.

\section{Compound preparation}

The Bu-7 compound was prepared as previously described ${ }^{[17]}$. Briefly, the air-dried leaves $(0.8 \mathrm{~kg})$ of Clausena lansium were extracted with $70 \%$ ethanol for $2 \mathrm{~h}$ under reflux conditions, and the $70 \%$ ethanol extract was concentrated under reduced pressure. Subsequently, it was partitioned with petroleum ether $\left(60-90^{\circ} \mathrm{C}\right)$, ethyl acetate and butyl alcohol, respectively.
The butyl alcohol portion (50 g) was chromatographed over a silica gel column using ethyl acetate-methanol as the gradient eluent $(50: 1-1: 1, v / v)$ to produce 32 fractions. Fractions 20-27 were subjected to RP-18 column chromatography and eluted using a gradient of methanol- $\mathrm{H}_{2} \mathrm{O}(30 \%-70 \%, v / v)$ to 20 fractions. Fraction $11(1.1 \mathrm{~g})$ was subjected to column chromatography on silica gel and eluted with $\mathrm{CHCl}_{3}$-methanol- $\mathrm{H}_{2} \mathrm{O}$ $(8: 2.5: 0.3, v / v / v)$ to yield several fractions. Fractions 6-8 (502 $\mathrm{mg}$ ) were again subjected to RP-18 column chromatography and eluted using a gradient of methanol- $\mathrm{H}_{2} \mathrm{O}(20 \%-50 \%, v / v)$ to yield fractions $\mathrm{A}$ and B. Fraction A was subjected to a Sephadex LH-20 column using 70\% methanol- $\mathrm{H}_{2} \mathrm{O}$ and purified using high-pressure liquid chromatography (HPLC) (YMCPack ODS-A column [20 mm $\times 250 \mathrm{~mm}, 5 \mu \mathrm{m}]$ ) with $13 \%$ acetonitrile- $\mathrm{H}_{2} \mathrm{O}(0.05 \% \mathrm{TFA})$ to yield Bu-7 (17 mg).

\section{Cell culture}

PC12 cells were purchased from the American Type Culture Collection (ATCC). The cells were cultured in Dulbecco's modified Eagle's medium (Invitrogen, Gibco, USA) supplemented with 5\% heat-inactivated fetal bovine serum (Invitrogen, Gibco, USA), $5 \%$ equine serum (Thermo Scientific, Hyclone, USA), $100 \mathrm{U} / \mathrm{mL}$ penicillin and $100 \mathrm{\mu g} / \mathrm{mL}$ streptomycin. The cultures were maintained in a humidified incubator at $37{ }^{\circ} \mathrm{C}$ in an atmosphere of $95 \%$ air and $5 \% \mathrm{CO}_{2}$. The media were changed every two or three days.

\section{Drug treatments}

Rotenone and $\mathrm{Bu}-7$ were reconstituted fresh in dimethyl sulfoxide and distilled water, respectively, prior to each experiment. Bu-7 $(0.1,1,10 \mu \mathrm{mol} / \mathrm{L})$ was added $0.5 \mathrm{~h}$ prior to the rotenone treatment in the cell cultures to evaluate its protective effect.

\section{Cell viability assay}

Cell viability was determined using the MTT assay. After incubation with MTT solution for $4 \mathrm{~h}$, the cells were exposed to an MTT-formazan dissolving solution for 8-12 h. The optical density $(O D)$ was then determined using an absorbance microplate reader (Molecular Devices, Toronto, Canada) at a wavelength of $570 \mathrm{~nm}$. The cell viability was expressed as a percentage of the $O D$ value of the control cultures.

\section{Analysis of apoptosis by flow cytometry}

The apoptosis rate was measured by flow cytometry, as reported previously ${ }^{[20]}$. Briefly, PC12 cells were washed with PBS ( $\mathrm{pH} 7.4)$, fixed in cold 70\% (v/v) ethanol, and incubated at $-20^{\circ} \mathrm{C}$ for at least $2 \mathrm{~h}$. The fixed cells were harvested by centrifugation at $250 \times \mathrm{g}$ for $5 \mathrm{~min}$. The cell pellets were resuspended in PBS at room temperature for $10 \mathrm{~min}$, and after another centrifugation, the cell pellets were resuspended in PBS containing $0.2 \mathrm{~g} / \mathrm{L}$ RNase A and incubated at $37^{\circ} \mathrm{C}$ for 30 min. The cells were then stained with propidium iodide (PI) at a final concentration of $100 \mathrm{\mu g} / \mathrm{mL}$ at $4{ }^{\circ} \mathrm{C}$ for $30 \mathrm{~min}$. The suspensions were analyzed using a FACS scan flow cytometer (Becton Dickinson). 
Measurement of mitochondrial membrane potential (MMP)

Changes in the inner MMP were determined by incubating with $10 \mu \mathrm{g} / \mathrm{mL}$ of Rhodamine 123 for $30 \mathrm{~min}$ at $37^{\circ} \mathrm{C}$ in the dark. The cells were then washed with PBS three times, and the fluorescence intensity was determined using flow cytometry. JC-1 was also used to measure the change of the inner MMP. PC12 cells were incubated with $10 \mu \mathrm{g} / \mathrm{mL}$ JC- 1 at $37^{\circ} \mathrm{C}$. JC-1 accumulates in the mitochondria, forming red fluorescent aggregates at high membrane potentials; at a low membrane potential, JC-1 exists mainly in the green fluorescent, monomeric form. After incubating for $20 \mathrm{~min}$, the cells were washed with PBS for 3 times and submitted to fluorescence microscopy analysis. The JC-1-loaded cells were excited at 488 $\mathrm{nm}$, and the emission was detected at $590 \mathrm{~nm}$ (JC-1 aggregates) and $525 \mathrm{~nm}$ (JC-1 monomers). Mitochondrial depolarization was indicated by an increase in the green/red fluorescence intensity ratio, which was calculated with Image J software.

\section{Western blot analysis}

After treatment, the cells were washed with PBS and lysed in lysis buffer $(50 \mathrm{mmol} / \mathrm{L}$ Tris- $\mathrm{HCl}, 150 \mathrm{mmol} / \mathrm{L} \mathrm{NaCl}, 1 \%$ NP-40, $1 \mathrm{mmol} / \mathrm{L}$ PMSF, $50 \mu \mathrm{g} / \mathrm{mL}$ leupeptin, $1 \mu \mathrm{g} / \mathrm{mL}$ pepstatin A, $20 \mu \mathrm{g} / \mathrm{mL}$ aprotinin, $1 \mathrm{mmol} / \mathrm{L}$ EDTA, $1 \mathrm{mmol} / \mathrm{L}$ EGTA, $1 \mathrm{mmol} / \mathrm{L} \mathrm{DTT,} 1 \mathrm{mmol} / \mathrm{L} \mathrm{Na}_{3} \mathrm{VO}_{4}, 50 \mathrm{mmol} / \mathrm{L} \mathrm{NaF}$, and $20 \mathrm{mmol} / \mathrm{L} \beta$-glycerophosphate $\mathrm{Na}_{2}, \mathrm{pH}$ 8.0). The protein concentrations were measured with a BCA kit (Pierce). The cell lysates were solubilized in SDS sample buffer, separated by SDS-PAGE and transferred to a PVDF membrane (Millipore). The membrane was blocked with 3\% BSA and incubated with the primary antibody, anti-JNK/p-JNK MAPK, anti-p38/p-p38 MAPK, anti-p53, anti-Bax, anti-Bcl-2, or anticaspase 3, followed by a horseradish peroxidase (HRP)conjugated secondary antibody. The proteins were detected using the enhanced chemiluminescence plus detection system (Molecular Device, Lmax) and analyzed with Science Lab 2005 Image Gauge software. $\beta$-Actin served as an internal control.

\section{Statistical analysis}

All of the data obtained in the experiments were represented as the mean \pm standard deviation (SD). The statistical analysis was performed using the SPSS 13.0 software package. Differences were determined using one-way analysis of variance (ANOVA), and $P$ values of less than 0.05 and 0.01 were regarded as statistically significant.

\section{Results}

\section{Bu-7 protects against rotenone-induced PC12 cell death}

To investigate how rotenone influences neuronal cytotoxicity, PC12 cells were treated with various concentrations of rotenone $(0,0.1,1,5,10$, or $20 \mu \mathrm{mol} / \mathrm{L})$ for $24 \mathrm{~h}$. As shown in Figure $2 \mathrm{~A}$, rotenone induced a dose-dependent cytotoxicity in the PC12 cells. The cells were then treated for $24 \mathrm{~h}$ with various concentrations of Bu-7 with or without rotenone $(1 \mu \mathrm{mol} / \mathrm{L})$ to determine the effect of Bu-7 on the rotenone-induced cytotoxicity. The cells treated with rotenone demonstrated a viability of $69.2 \% \pm 3.0 \%$. We found that $\mathrm{Bu}-7$ had a dose-dependent
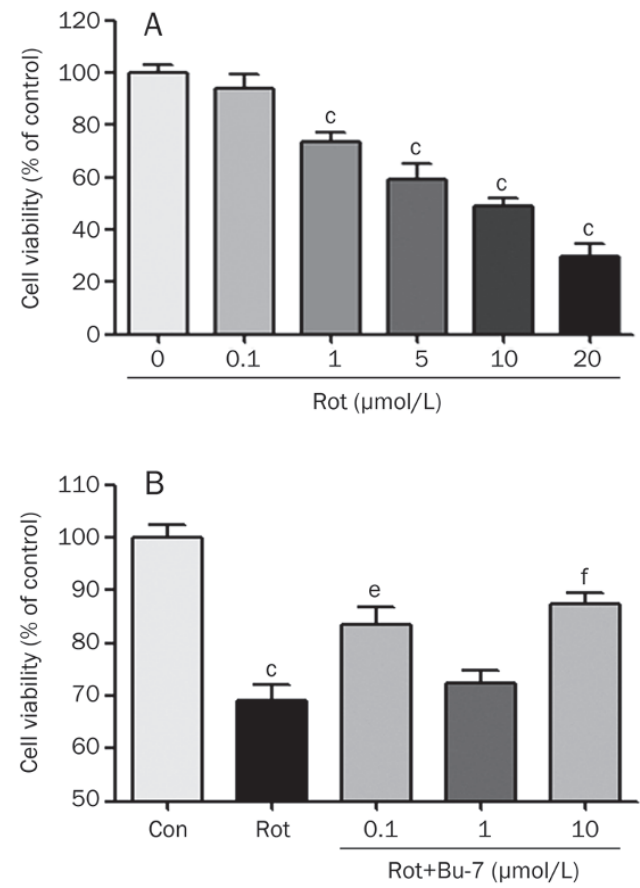

Figure 2. Bu-7 reduces rotenone (Rot)-induced cell death. (A) PC12 cells were treated with various concentrations of Rot for $24 \mathrm{~h}$. (B) The effect of Bu-7 was examined on PC12 cells treated with $1 \mu \mathrm{mol} / \mathrm{L}$ Rot for $24 \mathrm{~h}$. PC12 cells were exposed to different concentrations ( $0.1,1$, and $10 \mu \mathrm{mol} /$ L) of Bu-7 and Rot. The cell viability was evaluated by MTT assay. $n=6$. Mean \pm SD. ${ }^{c} P<0.01$ vs control. ${ }^{e} P<0.05,{ }^{f} P<0.01$ vs Rot-treated group.

effect on cell viability after the rotenone treatment (Figure $2 \mathrm{~B})$, increasing the viability of the PC12 cells to $83.6 \% \pm 3.2 \%$, $72.3 \% \pm 2.4 \%$, and $87.3 \% \pm 2.3 \%$ at a concentration of $0.1,1$ and $10 \mu \mathrm{mol} / \mathrm{L}$, respectively, compared with the control group.

\section{Bu-7 protects against rotenone-induced apoptosis}

To determine how $\mathrm{Bu}-7$ protects cells against rotenone, the PC12 cells were stained with propidium iodide (PI) and then analyzed using flow cytometry. The PC12 cells treated with rotenone $(1 \mu \mathrm{mol} / \mathrm{L}, 24 \mathrm{~h})$ showed an obvious apoptosis rate of $30.0 \% \pm 1.0 \%$, whereas Bu-7 treatment of the cells $(0.1,1$, and $10 \mu \mathrm{mol} / \mathrm{L})$ significantly attenuated rotenone-induced apoptosis $(21.6 \% \pm 0.2 \%, 26.2 \% \pm 1.4 \%$, and $21.2 \% \pm 0.4 \%$, respectively, Figure 3).

Bu-7 attenuated the rotenone-induced mitochondrial potential reduction in $\mathrm{PC} 12$ cells

Normal PC12 cells stained with the JC-1 dye emitted a mitochondrial orange-red fluorescence with a small amount of green fluorescence. These JC-1 aggregates within the normal mitochondria were dispersed to the monomeric form (green fluorescence) after the addition of $1 \mu \mathrm{mol} / \mathrm{L}$ rotenone in the culture medium for $24 \mathrm{~h}(122.1 \% \pm 8.2 \%)$. However, Bu-7 relieved the rotenone-induced mitochondrial depolarization, as shown by the fluorescent color changes from green to orange-red $(87.1 \% \pm 5.3 \%, 107.0 \% \pm 4.7 \%$, and $90.2 \% \pm 2.6 \%$, 
A

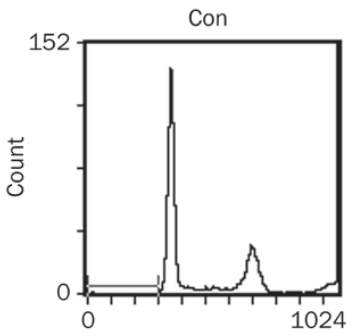

B

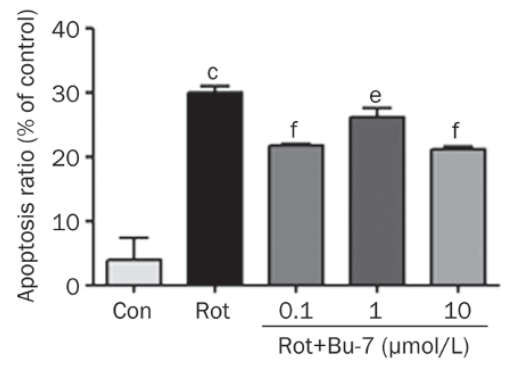

respectively, Figure 4). These data showed that rotenone induced mitochondrial membrane permeabilization and caused collapse of the MMP in PC12 cells, whereas Bu-7 significantly attenuated this response.

Bu-7 suppresses the levels of apoptotic proteins associated with p53 in rotenone injured PC12 cells, which is partly through the MAPK signaling pathway

The MAPK signaling pathway may be involved in the intrinsic mitochondrial apoptosis pathway. The effect of Bu-7 on the expression levels of apoptotic proteins was determined using
Figure 3. Effect of Bu-7 on Rot-induced apoptosis/necrosis staining with $\mathrm{Pl}$ analyzed by flow cytometry. (A) Rot $(1 \mu \mathrm{mol} / \mathrm{L})$ induced the increase of apoptosis/necrosis of PC12 cells for $24 \mathrm{~h}$ incubation. However, this trend was inhibited by Bu-7. (B) Quantitative analysis of the ratio of apoptosis/ necrosis. Mean \pm SD. ${ }^{c} P<0.01$ vs control. ${ }^{e} P<0.05,{ }^{f} P<0.01$ vs Rot-treated group.

Western blot analysis in PC12 cells exposed to rotenone. The rotenone treatment $(1 \mu \mathrm{mol} / \mathrm{L}, 24 \mathrm{~h})$ increased the phosphorylation status of JNK $(218.0 \% \pm 11.1 \%)$ and p38 $(215.6 \% \pm 42.0 \%)$, increased the expression of p53 (496.1\% $\pm 10.0 \%)$ and the ratio of Bax/Bcl-2 (264.2\% $\pm 16.1 \%)$, and increased the expression levels of cleaved (presumably active) caspase $3(219.1 \% \pm 25.0 \%)$. The pretreatment with Bu-7 $(0.1,1$, or $10 \mu \mathrm{mol} / \mathrm{L})$ prevented the rotenone-induced increase of the above proteins in the same dose-dependent manner as was observed in the cell viability and apoptosis experiments (Figure 5).
A
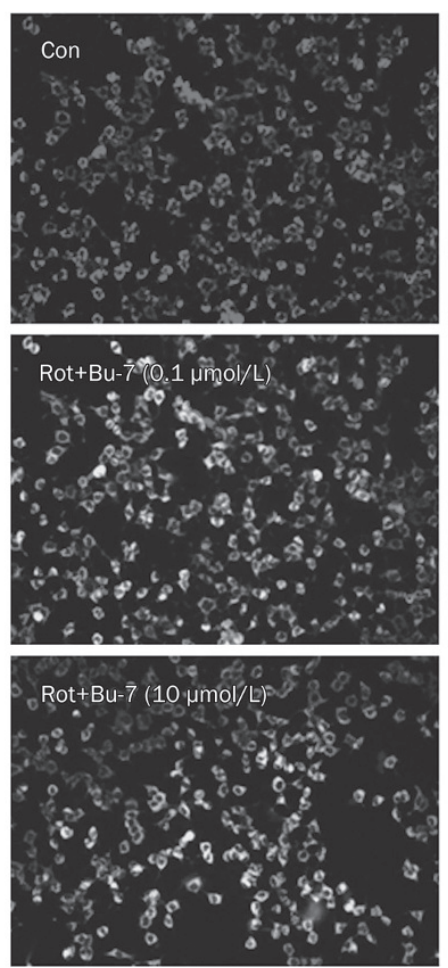
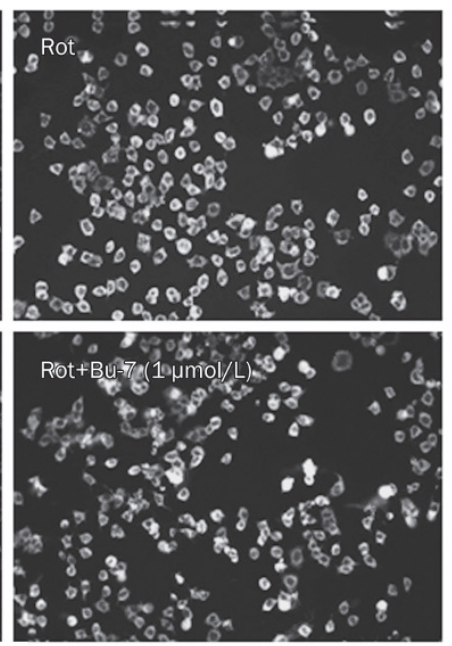

B

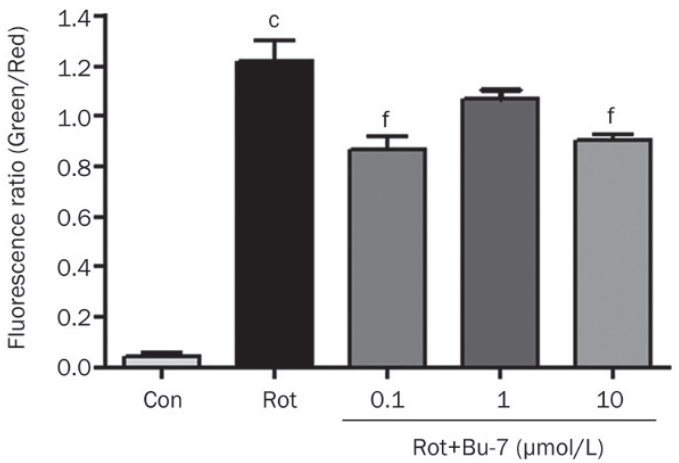

Figure 4. Bu-7 protected MMP of PC12 cells injured by Rot ( $1 \mu \mathrm{mol} / \mathrm{L})$. (A) Bu-7 prevented the decrease of MMP by JC-1 staining. (B) Quantitative analysis of the fluorescence ratio of green/red. ${ }^{C} P<0.01$ vs control, ${ }^{\mathrm{f}} P<0.01$ vs Rot-treated group. 
A
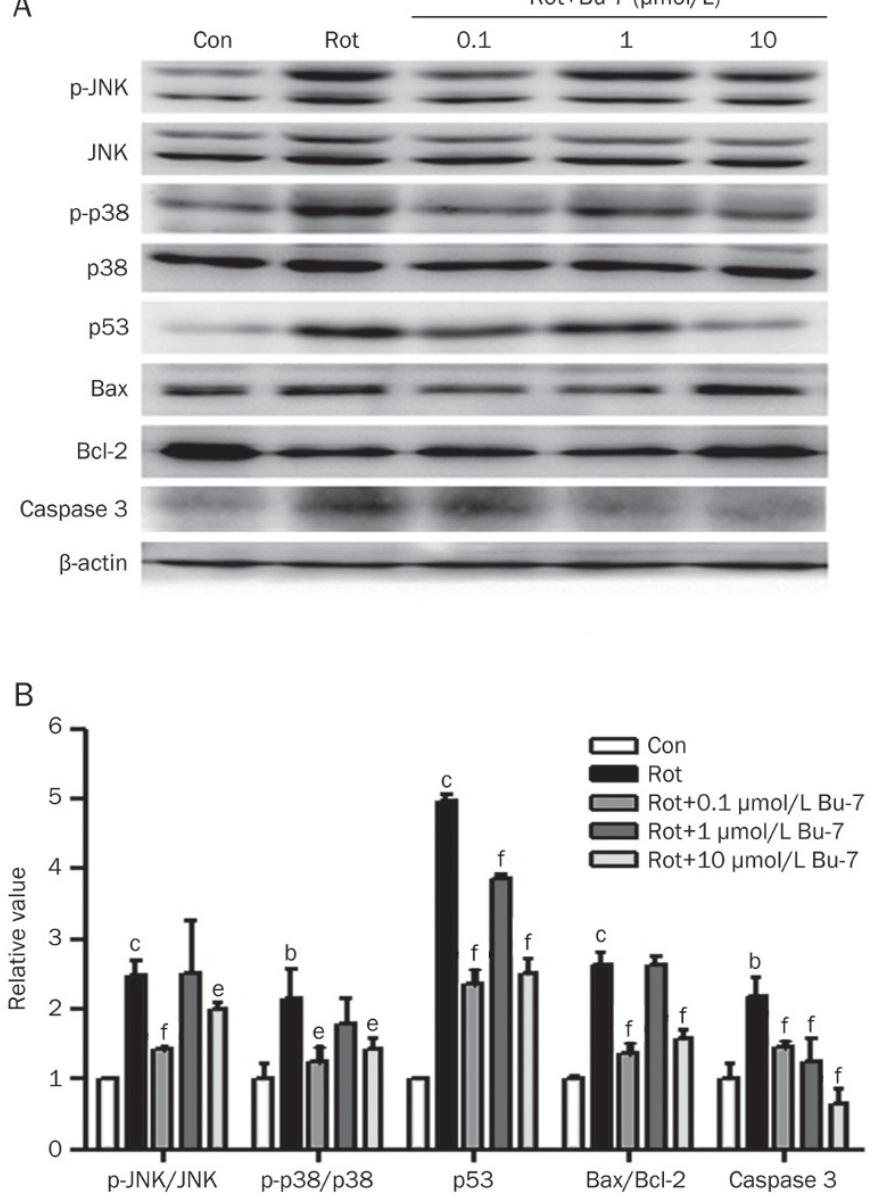

Figure 5. Effect of Bu-7 on the phosphorylation of JNK/p38 MAPK, the expression of p53, Bax, Bcl-2, and caspase 3 in PC12 cells exposed to Rot. (A) PC12 cells were lysed after treatment with Bu-7 and Rot $(1 \mu \mathrm{mol} / \mathrm{L})$. Protein expressions were detected by Western blotting. (B) Quantitative analysis of the phosphorylation of JNK/p38 MAPK, the expression of p53, Bax, Bcl-2, and caspase 3 by Science Lab 2005 Image Gauge software. $n=3$. Mean \pm SD. ${ }^{b} P<0.05,{ }^{c} P<0.01$ vs control. ${ }^{e} P<0.05,{ }^{f} P<0.01$ vs Rottreated group.

\section{Discussion}

In our previous study, we found that $\mathrm{Bu}-7$ increased the cell viability of PC12 cells injured by rotenone, 6-OHDA, and $\mathrm{MPP}^{+}$by MTT assay (unpublished observations). It is well known that rotenone, 6-OHDA, and $\mathrm{MPP}^{+}$cause neurotoxicity in cells in vitro ${ }^{[21,22]}$; thus, our previous data suggested that $\mathrm{Bu}-7$ may have a positive effect on anti-apoptosis and mitochondrial protection. Therefore, in our present study, we utilized rotenone to create an in vitro cell model to study the protective effects of Bu-7 in PC12 cells and tried to find the possible underlying mechanisms.

Mitochondria are involved in cell survival and play a central role in apoptotic cell death signaling through the control of cellular energy metabolism, the generation of reactive oxygen species (ROS), and the release of apoptotic factors into the cytosol. Evidence showed that ROS are involved in the apop- totic mechanism of rotenone-mediated neurotoxicity ${ }^{[23]}$. The mitochondrial membrane permeability transition induces the formation of ROS by the inhibition of the respiratory chain and vice versa ${ }^{[2]}$. Our data showed that $\mathrm{Bu}-7$ protected PC12 cell viability, decreased the apoptosis rate and attenuated the collapse of the MMP induced by rotenone in a manner that resembled an inverted bell-shaped curve. The results demonstrated that $\mathrm{Bu}-7$ had a protective effect against rotenone injury in PC12 cells.

We then further investigated the protective mechanisms of Bu-7 against rotenone-induced apoptosis. Previous evidence from both postmortem PD brain tissues and cellular and animal models suggested that pathways involving p53/Bcl-2family members may represent suitable targets in apoptosis in $\mathrm{PD}^{[25-29]}$. The activation of JNK and p38 were reported to be responsible for p53-dependent apoptosis including the inhibition of the anti-apoptotic Bcl-2 protein, which further promoted the caspase process, which had a general role in rotenone-induced apoptosis in neuronal cells ${ }^{[30]}$. It was observed in SH-SY5Y cells that rotenone induced apoptosis through the activation of the JNK and p38 signaling pathways, which indicated their role in neuronal apoptosis ${ }^{[31-34]}$. Our results showed that rotenone $(1 \mu \mathrm{mol} / \mathrm{L})$ induced the phosphorylation of JNK and p38 after treatment for $24 \mathrm{~h}$. Bu-7 pretreatment inhibited the rotenone-induced phosphorylation of both JNK and p38 and decreased the p53 level that was increased by rotenone. Bu-7 also prevented the increase of the Bax/Bcl-2 ratio and the increase of caspase 3 activity in the rotenonetreated PC12 cells. These results indicated that $\mathrm{Bu}-7$ prevented the rotenone-induced apoptosis that is associated with the p53 pathway, which might occur through the inhibition of JNK and p38 activities.

Our experiments showed that the dose-response relationship of Bu-7 resembled an inverted bell-shaped curve. This kind of dose-response relationship has been reported previously $^{[21,35,36]}$. It is common that a chemical binds to two or more targets/receptors with different affinities. At different doses, the compound may activate different receptors and produce different effects, even opposite ones, in which case, the dose-response relationship is irregular. Further research is required to identify the receptors in an effort to explain the inverted bell-shaped dose-response relationship for Bu-7.

In conclusion, we isolated Bu-7 from extracts of Clausena lansium leaves ${ }^{[17]}$ and our present observations identified a beneficial role of Bu-7 against rotenone-induced apoptosis in PC12 cells that may operate via an inhibition of the p38/JNK pathway. Epidemiological studies revealed a correlation between general pesticide (ie, rotenone) exposure and an increased risk of PD; therefore, our findings suggested that $\mathrm{Bu}-7$ could be used as a leading compound that might be useful for the treatment of PD. Because our research demonstrated the utility of the bioactive substances in Clausena lansium, we are systematically extracting and separating additional compounds from Clausena lansium leaves to find out chemicals which have higher bioactivities than Bu-7; at the same time, we are attempting to chemically modify $\mathrm{Bu}-7$ to obtain an increased 
bioactivity.

\section{Acknowledgements}

This work was supported by the National Natural Science Foundation of China (№ 30973887, 81073078, 81073130, Key Program No U832008 and 90713045), National Sci-Tech Major Special Item for New Drug Development (No 2008ZX09101, 2009ZX09303, 2009ZX09303-003, and 2009ZX09301-003-111) and Doctoral Fund of Ministry of Education of China (No 20070023037).

\section{Author contribution}

Bo-yu LI designed the study, performed the research, and wrote the paper; Yu-he YUAN and Jin-feng HU provided assistance in experimental methods; Dong-ming ZHANG and Qing ZHAO extracted Bu-7; and Nai-hong CHEN designed the research and revised the paper.

\section{References}

1 Forno LS. Neuropathology of Parkinson's disease. J Neuropathol Exp Neurol 1996; 55: 259-72.

2 Betarbet R, Sherer TB, MacKenzie G, Garcia-Osuna M, Panov AV, Greenamyre JT. Chronic systemic pesticide exposure reproduces features of Parkinson's disease. Nat Neurosci 2000; 3: 1301-6.

3 Lees AJ, Hardy J, Revesz T. Parkinson's disease. Lancet 2009; 373: 2055-66.

4 Betarbet R, Sherer TB, Greenamyre JT. Animal models of Parkinson's disease. Bioessays 2002; 24: 308-18.

5 Uversky VN. Neurotoxicant-induced animal models of Parkinson's disease: understanding the role of rotenone, maneb and paraquat in neurodegeneration. Cell Tissue Res 2004; 318: 225-41.

6 Priyadarshi A, Khuder SA, Schaub EA, Priyadarshi SS. Environmental risk factors and Parkinson's disease: a metaanalysis. Environ Res 2001; 86: 122-7.

7 Vanacore N, Nappo A, Gentile M, Brustolin A, Palange S, Liberati A, et al. Evaluation of risk of Parkinson's disease in a cohort of licensed pesticide users. Neurol Sci 2002; 23: S119-20.

8 Chance B, Williams GR, Hollunger G. Inhibition of electron and energy transfer in mitochondria. I. Effects of Amytal, thiopental, rotenone, progesterone, and methylene glycol. J Biol Chem 1963; 238: 418-31.

9 Hartley A, Stone JM, Heron C, Cooper JM, Schapira AH. Complex I inhibitors induce dose-dependent apoptosis in PC12 cells: relevance to Parkinson's disease. J Neurochem 1994; 63: 1987-90.

10 Tapias V, Cannon JR, Greenamyre JT. Melatonin treatment potentiates neurodegeneration in a rat rotenone Parkinson's disease model. J Neurosci Res 2010; 88: 420-7.

11 Monti B, Gatta V, Piretti F, Raffaelli SS, Virgili M, Contestabile A. Valproic acid is neuroprotective in the rotenone rat model of Parkinson's disease: involvement of alpha-synuclein. Neurotox Res 2010; 17: 130-41.

12 Valverde G De Andrade D, Madureira de Oliveria D, Barreto G, Bertolino LA, Saraceno E, Capani F, et al. Effects of the extract of Anemopaegma mirandum (Catuaba) on Rotenone-induced apoptosis in human neuroblastomas SH-SY5Y cells. Brain Res 2008; 1198: 188-96.

$13 \mathrm{Kim} \mathrm{HJ}$, Park HJ, Park HK, Chung JH. Tranexamic acid protects against rotenone-induced apoptosis in human neuroblastoma SH-SY5Y cells. Toxicology 2009; 262: 171-4.

14 Liu GT, Li WX, Chen YY, Wei HL. Hepatoprotective action of nine constituents isolated from the leaves of Clausena lansium in mice. Drug Dev Res 1996; 39: 174-8.

15 Zhang J, Cheng Y, Zhang JT. Protective effect of (-)clausenamide against neurotoxicity induced by okadaic acid and beta-amyloid peptide25-35. Yao Xue Xue Bao 2007; 42: 935-42.

16 Qian W, Wang LN, Song M, Zheng XW, Hang TJ, Zhang ZX. Excretion of (-)-clausenamide in rats. Yao Xue Xue Bao 2006; 41: 789-92.

17 Zhao Q, Li C, Yang J, Zhang D. Chemical constituents of Clausena lansium. Zhongguo Zhong Yao Za Zhi 2010; 35: 997-1000.

18 Guzhva N, Luk'yanchikov M, Ushakov V, Sarkisov L. Flavonoids of Astragalus captiosus. Chem Nat Compd 1986; 22: 729.

19 Greene LA, Tischler AS. Establishment of a noradrenergic clonal line of rat adrenal pheochromocytoma cells which respond to nerve growth factor. Proc Natl Acad Sci U S A 1976; 73: 2424-8.

20 Nicoletti I, Migliorati G, Pagliacci MC, Grignani F, Riccardi C. A rapid and simple method for measuring thymocyte apoptosis by propidium iodide staining and flow cytometry. J Immunol Methods 1991; 139: 271-9.

21 Zhang ZT, Cao XB, Xiong N, Wang HC, Huang JS, Sun SG, et al. Morin exerts neuroprotective actions in Parkinson disease models in vitro and in vivo. Acta Pharmacol Sin 2010; 31: 900-6.

22 Lin CM, Lin RD, Chen ST, Lin YP, Chiu WT, Lin JW, et al. Neurocytoprotective effects of the bioactive constituents of Pueraria thomsonii in 6-hydroxydopamine (6-OHDA)-treated nerve growth factor (NGF)differentiated PC12 cells. Phytochemistry 2010; 71: 2147-56.

23 Tan S, Sagara Y, Liu Y, Maher P, Schubert D. The regulation of reactive oxygen species production during programmed cell death. J Cell Biol 1998; 141: 1423-32.

24 Polster BM, Fiskum G. Mitochondrial mechanisms of neural cell apoptosis. J Neurochem 2004; 90: 1281-9.

25 Mattson MP. Apoptosis in neurodegenerative disorders. Nat Rev Mol Cell Biol 2000; 1: 120-9.

26 Waldmeier PC. Prospects for antiapoptotic drug therapy of neurodegenerative diseases. Prog Neuropsychopharmacol Biol Psychiatry 2003; 27: 303-21.

27 Reed JC. Apoptosis-based therapies. Nat Rev Drug Discov 2002; 1: 111-21.

28 Ferri KF, Kroemer G. Organelle-specific initiation of cell death pathways. Nat Cell Biol 2001; 3: E255-63.

29 Zimmermann KC, Bonzon C, Green DR. The machinery of programmed cell death. Pharmacol Ther 2001; 92: 57-70.

30 Pei W, Liou AK, Chen J. Two caspase-mediated apoptotic pathways induced by rotenone toxicity in cortical neuronal cells. FASEB J 2003; 17: 520-2.

31 Caughlan A, Newhouse K, Namgung U, Xia Z. Chlorpyrifos induces apoptosis in rat cortical neurons that is regulated by a balance between p38 and ERK/JNK MAP kinases. Toxicol Sci 2004; 78: 125-34.

32 Newhouse K, Hsuan SL, Chang SH, Cai B, Wang Y, Xia Z. Rotenoneinduced apoptosis is mediated by $\mathrm{p} 38$ and JNK MAP kinases in human dopaminergic SH-SY5Y cells. Toxicol Sci 2004; 79: 137-46.

33 Junn E, Mouradian MM. Apoptotic signaling in dopamine-induced cell death: the role of oxidative stress, p38 mitogen-activated protein kinase, cytochrome c and caspases. J Neurochem 2001; 78: 374-83.

34 Davis RJ. Signal transduction by the JNK group of MAP kinases. Cell 2000; 103: 239-52.

35 Dai G, Huang C, Li Y, Pi YH, Wang BH. Inhibitory effects of AcSDKP on proliferation of human bone marrow mesenchymal stem cells in vitro. Sheng Li Xue Bao 2006; 58: 110-5.

36 Gao M, Liu R, Zhu SY, Du GH. Acute neurovascular unit protective action of pinocembrin against permanent cerebral ischemia in rats. J Asian Nat Prod Res 2008; 10: 551-8. 